\title{
Patogenicidad de una cepa de Yersinia ruckeri de un brote de yersiniosis en truchas arcoíris (Oncorhynchus mykiss) de Huaraz, Perú
}

\section{Pathogenicity of a Yersinia ruckeri strain from an outbreak of yersiniosis in rainbow trout (Oncorhynchus mykiss) from Huaraz, Peru}

\author{
Fernando Mesías V. ${ }^{1}$, Mario Vargas L. ${ }^{1}$, Alexander Cueva Q. ${ }^{1}$, \\ Alberto Manchego S. ${ }^{2}$, Nieves Sandoval C.,3
}

\section{Resumen}

\begin{abstract}
El presente estudio tuvo como objetivos determinar la patogenicidad de una cepa de Yersinia ruckeri, procedente de un brote de yersiniosis en Huaraz y caracterizar las lesiones histopatológicas en diversos órganos de alevines de trucha arcoíris (Oncorhynchus mykiss). Se utilizaron 100 alevines con peso promedio de $7.25 \mathrm{~g}$, divididos en 5 grupos de 20 individuos (cuatro experimentales y un control), mantenidos en estanques de $30 \mathrm{~L}$. Los grupos experimentales fueron inoculados vía i.m. con $0.1 \mathrm{ml}$ de la cepa bacteriana en concentraciones de $1 \times 10^{4} / \mathrm{ml}(\mathrm{G} 1), 4 \times 10^{4} / \mathrm{ml}(\mathrm{G} 2), 1 \times 10^{8} / \mathrm{ml}(\mathrm{G} 3)$ y $4 \times 10^{8} / \mathrm{ml}$ (G4). y el grupo control con PBS. Los signos clínicos, lesiones externas e internas, morbilidad y mortalidad se registraron durante 12 días pos-inoculación. Se colectaron muestras de hígado, intestino, bazo, riñón, músculo y branquias para el análisis histopatológico. Todos los peces inoculados con $Y$. ruckeri presentaron signos y lesiones compatibles con yersiniosis; registrándose mayormente inapetencia y melanosis, así como esplenomegalia, contenido mucoso en intestino y congestión intestinal. Las mortalidades fueron del 65 y $60 \%$ para G1 y G2, respectivamente, y de $100 \%$ para G3 y G4. A nivel histopatológico, se halló degeneración grasa en hígado, necrosis en intestino y músculo, presencia de melanomacrófagos y congestión en bazo y riñón, hiperplasia y fusión de lamelas en branquias. Los resultados indican que la cepa de Y. ruckeri procedente de Huaraz es altamente patógena.
\end{abstract}

Palabras clave: Yersinia ruckeri; trucha arcoíris; patogenicidad; enfermedad de la boca roja

\footnotetext{
${ }^{1}$ Laboratorio de Histología, Embriología y Patología Veterinaria, Facultad de Medicina Veterinaria, Universidad Nacional Mayor de San Marcos, Lima, Perú

${ }^{2}$ Laboratorio de Microbiología y Parasitología Veterinaria, Facultad de Medicina Veterinaria, Universidad Nacional Mayor de San Marcos, Lima, Perú

${ }^{3}$ E-mail: nsandovalc@unmsm.edu.pe
}

Recibido: 3 de julio de 2018

Aceptado para publicación: 22 de noviembre de 2018 
The objectives of this study were to determine the pathogenicity of a strain of Yersinia ruckeri, from an outbreak of yersiniosis in Huaraz and to characterize histopathological lesions in various organs of rainbow trout fingerlings (Oncorhynchus mykiss). One hundred fingerlings with an average weight of $7.25 \mathrm{~g}$ were used, divided into 5 groups of 20 individuals (four experimental and one control), kept in $30 \mathrm{~L}$ ponds. Experimental groups were inoculated via i.m. with $0.1 \mathrm{ml}$ of the bacterial strain in concentrations of $1 \times 10^{4} / \mathrm{ml}(\mathrm{G} 1), 4 \times 10^{4} / \mathrm{ml}(\mathrm{G} 2), 1 \times 10^{8} / \mathrm{ml}(\mathrm{G} 3)$ and $4 \times 10^{8} / \mathrm{ml}(\mathrm{G} 4)$, and the control group with PBS. Clinical signs, external and internal lesions, morbidity and mortality were recorded for 12 days post-inoculation. Samples of liver, intestine, spleen, kidney, muscle and gills were collected for histopathological analysis. All fish inoculated with $Y$. ruckeri showed signs and lesions compatible with yersiniosis. Most of individuals had inappetence and melanosis, as well as splenomegaly, mucous content in the intestine and intestinal congestion. Mortalities were 65 and $60 \%$ for G1 and G2, respectively and $100 \%$ for G3 and G4. Fat degeneration was found in liver, necrosis in intestine and muscle, presence of melanomacrophages and congestion in spleen and kidney, hyperplasia and fusion of lamellae in gills. Results indicate that $Y$. ruckeri strain from Huaraz is highly pathogenic.

Key words: Yersinia ruckeri; rainbow trout; pathogenicity; redmouth disease

\section{INTRODUCCIÓN}

La enfermedad de la boca roja o yersiniosis es causada por Yersinia ruckeri, una bacteria que afecta a principalmente a salmónidos, ocasionando una infección sistémica de curso agudo a crónico con altas mortalidades y grandes pérdidas económicas (Austin B y Austin D, 2016). La enfermedad se caracteriza por la presencia de hemorragias alrededor de la boca y el ano, base de las aletas y en la superficie de los órganos internos (Barnes, 2011; Kumar et al., 2015). La enfermedad de la boca roja se reconoció por primera vez como una enfermedad bacteriana grave en una piscigranja de truchas arcoíris en los EEUU a comienzos de la década de 1950 (Rucker, 1966). Actualmente, la yersiniosis tiene una distribución mundial (Tobback et al., 2007; Barnes, 2011). En Perú, la primera vez que se aisló $Y$. ruckeri fue en Junín por Bravo y Kojagura (2004), y posteriormente en otros departamentos de la sierra central, norte y sur del país (Sirvas et al., 2011; Flores; 2013; Sandoval et al., 2016; Cerro et al., 2017; Castro et al., 2017).
Y. ruckeri es una bacteria bacilar gramnegativa y mayormente móvil (Tobback et al., 2007). La trucha arcoíris (Oncorhynchus mykiss) es la especie más susceptible a este agente bacteriano (Tobback et al., 2007; Barnes, 2011); sin embargo, se ha informado de infecciones por $Y$. ruckeri en otros salmónidos y otras especies de peces (Willumsen, 1989; Kumar et al., 2015; Austin y Austin, 2016). La yersiniosis es más contagiosa a temperaturas del agua de $15-20{ }^{\circ} \mathrm{C}$, siendo de 5 a 10 días el periodo de incubación de la infección (Busch y Lingg, 1975; Roberts, 1983). La transmisión de la enfermedad es principalmente de forma horizontal a través del agua por las deyecciones de peces enfermos o portadores (Busch, 1978; Kumar et al., 2015). Generalmente, la infección se observa en forma hiperaguda o aguda, especialmente en alevines, cuando hay un aumento repentino en la temperatura del agua en primavera, mientras que las infecciones crónicas generalmente ocurren en los peces adultos a principios del invierno (Busch, 1978; Barnes, 2011). 
La mayoría de las investigaciones previas sobre las infecciones por $Y$. ruckeri se basaron en los hallazgos bacteriológicos, habiéndose clasificado actualmente dos biotipos. El 1 que es móvil y secreta fosfolipasa, y el biotipo 2 que ha perdido la motilidad y secreción de la fosfolipasa (Welch et al., 2011); además de diversos serotipos en base del antígeno $\mathrm{O}$ del lipopolisacárido de la bacteria (Davies, 1990). Sin embargo, la investigación sobre la patogenicidad de las diferentes cepas de Y. ruckeri en truchas arcoíris es muy limitada (Avci y Birincioglu, 2005). En el Perú, se ha determinado la variabilidad fenotípica y bioquímica en aislados de $Y$. ruckeri de las principales regiones productoras de truchas arcoíris (Flores, 2013), pero no se han hecho estudios sobre su patogenicidad. Esto es importante con el fin de desarrollar las vacunas más adecuadas. Debido a esto, el objetivo de este estudio fue determinar la patogenicidad de una cepa de $Y$.ruckeri procedente de un brote en una piscigranja de truchas arcoíris de Huaraz.

\section{MATERIALes y Métodos}

\section{Tipo y Lugar de Estudio}

El estudio fue de tipo experimental, descriptivo, longitudinal y prospectivo. La preparación de los inóculos bacterianos, los análisis bacteriológicos y moleculares, y los análisis de láminas histopatológicas se realizaron en la Sección de Ictiopatología de la Facultad de Medicina Veterinaria (FMV) de la Universidad Nacional Mayor de San Marcos (UNMSM), en Lima, Perú. La crianza de los alevines de truchas arcoíris, la inoculación con $Y$. ruckeri y la evaluación de su efecto se llevaron a cabo en la Unidad de Cultivo Experimental del Laboratorio de Biología Acuática y Acuicultura de la Facultad de Ciencias Biológicas, UNMSM, Lima.

\section{Peces}

Se adquirió un lote de 120 alevines de trucha arcoíris (Oncorhynchus mykiss) en 2015 , con un peso de $7.25 \mathrm{~g}$ y talla promedio de $6.8 \mathrm{~cm}$, de una piscigranja ubicada en Canta, Lima, sin reporte alguno de enfermedad. Los peces fueron aclimatados por 10 días en un estanque de $500 \mathrm{~L}$ con aireación, filtración y enfriamiento constante del agua. Se les alimentó diariamente con una dieta comercial. Para asegurar que los peces estuvieran libres de $Y$. ruckeri, 20 truchas fueron anestesiadas con benzocaína $1 \mathrm{~g} / 201$ (Ross L y Ross B, 2008) y eutanasiadas mediante corte medular con hoja de bisturí entre el cerebro y la médula espinal (Rosenthal, 2013), tomándose luego muestras de bazo y riñón para el aislamiento bacteriológico en tripticasa de soya (TSA). El aislamiento de Y. ruckeri fue negativo.

\section{Cepa Desafío y Preparación del Inóculo}

Para la inoculación se utilizó una cepa de $Y$. ruckeri aislada de truchas arcoíris de cultivo con signos clínicos de yersiniosis de la región de Huaraz, Perú. La cepa estaba almacenada a $-20{ }^{\circ} \mathrm{C}$, fue descongelada y reactivada en caldo de tripticasa de soya (TSB) a $25^{\circ} \mathrm{C}$ por $24 \mathrm{~h}$, sembrada en TSA e incubada en las mismas condiciones. Las colonias características de $Y$. ruckeri se utilizaron para preparar diluciones bacterianas en buffer fosfato salino (PBS) estéril, hasta obtener las concentraciones requeridas para el presente estudio (Cuadro 1), medido según escala de McFarland a diluciones sucesivas.

\section{Diseño Experimental}

Los peces fueron distribuidos al azar en cinco grupos de 20 peces cada uno, siendo un grupo control y cuatro desafiados. Cada grupo fue mantenido en dos acuarios de 10 individuos cada uno. Los peces fueron anestesiados, siguiendo el procedimiento descrito previamente, e inoculados con la cepa de $Y$. ruckeri debajo de la aleta dorsal, usando jeringas de tuberculina estéril para cada aplicación (Cuadro 1). El grupo control fue inoculado con PBS estéril. 
Cuadro 1. Grupos experimentales inoculados por vía intramuscular con cepas de Yersinia ruckeri $(\mathrm{n}=20$ truchas por grupo)

\begin{tabular}{cc}
\hline Grupo & Dosis \\
\hline Control $^{1}$ & $0.1 \mathrm{ml}$ \\
G1 & $0.1 \mathrm{ml} \mathrm{de} 1 \times 10^{4} / \mathrm{ml}$ \\
G2 & $0.1 \mathrm{ml} \mathrm{de} 4 \times 10^{4} / \mathrm{ml}$ \\
G3 & $0.1 \mathrm{ml} \mathrm{de} 1 \times 10^{8} / \mathrm{ml}$ \\
G4 & $0.1 \mathrm{ml} \mathrm{de} 4 \times 10^{8} / \mathrm{ml}$ \\
\hline
\end{tabular}

${ }^{1}$ Se inoculó PBS

\section{Lesiones Macroscópicas, Aislamiento e Identificación de $Y$. ruckeri}

Los peces fueron monitoreados tres veces al día (08:00, 12:00, 17:00) durante 12 días, registrándose los signos clínicos presentes. Los peces moribundos con signos compatibles con yersiniosis fueron anestesiados y eutanasiados para identificar lesiones externas, lo cual también se hizo a los peces que morían. Luego, se desinfectaba la superficie del pez con etanol al $70 \%$ y se realizaba la necropsia según la metodología descrita por Meyers (2009) para reconocer lesiones internas. Al finalizar el experimento (día 13), los peces sobrevivientes fueron eutanasiados para su evaluación y análisis bacteriológico e histopatológico. Adicionalmente, las instalaciones y el equipo utilizado se desinfectaron con 10000 ppm de cloro.

Las muestras para la caracterización histológica, colectadas en formol al 10\%, fueron tejidos de intestino, riñón, bazo, músculo, hígado y branquias, procedentes de cinco peces por grupo. Las láminas histológicas fueron teñidas con hematoxilina y eosina $(\mathrm{H}-$ E) mediante el método histológico convencional. Las láminas fueron observadas con un microscopio óptico de luz con aumentos de 10X, 40X y 100X para determinar lesiones patológicas. Los hallazgos fueron catego- rizados según el grado de afección por su extensión (normal, escaso, leve, moderado y severo) propuesto por Reimschuessel et al. (1992).

Se tomaron muestras asépticas de bazo y riñón para aislamiento bacteriano mediante siembras por agotamiento en placas con TSA e incubadas por $24 \mathrm{~h}$ a $25^{\circ} \mathrm{C}$. Se registró las características fenotípicas de las colonias resultantes, tales como forma, tamaño, bordes y color. A las colonias presuntivas de ser $Y$. ruckeri se les realizó tinción de Gram, prueba de oxidasa, catalasa y motilidad. Las bacterias con características bioquímicas de $Y$. ruckeri fueron confirmadas por PCR. Para ello, se hizo extracción de ADN utilizando el kit comercial PureLink Genomic DNA Mini Kit (Thermo Fisher Scientific), siguiendo las indicaciones del fabricante. Posteriormente, el PCR se realizó según el protocolo desarrollado por Gibello et al. (1999), que identifica un segmento de 575 pares de bases (pb) correspondientes al gen del ribosoma $16 \mathrm{~S}$ de $Y$. ruckeri. Los productos de PCR fueron visualizados por electroforesis en geles de agarosa al $1.5 \%$ y teñidos con $0.5 \mu \mathrm{g} / \mathrm{ml} \mathrm{de}$ bromuro de etidio sometidos a campo eléctrico de $90 \mathrm{~V} / \mathrm{m}$ durante 60 minutos. Finalmente, se compararon las bandas de ADN en el transiluminador (DNR Bio-Imaging Systems, EEUU).

\section{Análisis de Datos}

Se realizaron estimaciones de frecuencias de los signos clínicos, lesiones externas e internas, así como de los hallazgos histopatológicos, según Bland y Altman (1986).

\section{Consideraciones Éticas}

En el estudio se contemplaron las normas éticas para la investigación señaladas por el Comité de Ética y Bienestar Animal de la FMV-UNMSM. 
Cuadro 2. Frecuencia de signos clínicos en truchas arcoíris inoculadas con Yersinia ruckeri $(n=20$ peces por grupo)

\begin{tabular}{lcccccc}
\hline Signos clínicos & $\begin{array}{l}\text { G1 } \\
(\mathrm{n})\end{array}$ & $\begin{array}{l}\text { G2 } \\
(\mathrm{n})\end{array}$ & $\begin{array}{l}\text { G3 } \\
(\mathrm{n})\end{array}$ & $\begin{array}{l}\text { G4 } \\
(\mathrm{n})\end{array}$ & $\begin{array}{c}\text { Total de } \\
\text { casos }(\mathrm{n})\end{array}$ & $\begin{array}{c}\text { Frecuencia } \\
(\%)\end{array}$ \\
\hline Anorexia & 18 & 17 & 18 & 19 & 67 & 90 \\
Melanosis & 14 & 15 & 15 & 17 & 61 & 76 \\
Letargia & 10 & 11 & 13 & 13 & 47 & 59 \\
$\begin{array}{l}\text { Exoftalmia } \\
\text { Abdomen }\end{array}$ & 9 & 10 & 12 & 13 & 44 & 55 \\
dilatado & 7 & 8 & 10 & 10 & 35 & 44 \\
Nado errático & 5 & 5 & 8 & 9 & 27 & 34 \\
Orillamiento & 5 & 4 & 6 & 6 & 21 & 26 \\
\hline
\end{tabular}

G1: $1 \times 10^{4} ; \mathrm{G} 2: 4 \times 10^{4} ; \mathrm{G} 3: 1 \times 10^{8} ; \mathrm{G} 4: 4 \times 10^{8} / \mathrm{ml}$

\section{Resultados}

\section{Análisis Bacteriológico y Molecular}

En los cultivos en TSA de bazo y riñón se aislaron colonias pequeñas, redondas y de color crema de $1 \mathrm{~cm}$ de diámetro en promedio. Los análisis morfológicos y bioquímicos mostraron que los aislados eran bacilos gramnegativos, móviles y positivos para catalasa, pero negativo para oxidasa.

En los productos de amplificación de PCR se observaron bandas específicas con un tamaño molecular de aproximadamente $575 \mathrm{pb}$, indicativo confirmatorio de $Y$. ruckeri como agente causal de signos y lesiones en peces infectados con esta bacteria. No se aisló $Y$. ruckeri de bazo y riñón en los peces del grupo control.

\section{Evaluación de Patogenicidad}

Entre los signos clínicos registrados con mayor frecuencia se encuentra la anorexia $(90 \%)$ y la melanosis (76\%) (Cuadro 2), que aparecieron a las 12 horas de la inoculación en G3 y G4, y al $3^{\text {er }}$ día pos-inoculación (dpi) en G1 y G2 (Cuadro 3). Posteriormente, aparecieron letargia y nado errático a las $24 \mathrm{~h}$ de la inoculación en $\mathrm{G} 3$ y G4, y al $4^{\text {to }} \mathrm{dpi}$ en G1 y G2, junto con otros signos en menor frecuencia con el transcurrir de los días. Ala necropsia, las lesiones externas e internas más frecuentes fueron esplenomegalia (86\%), contenido mucoso en intestino ( $80 \%)$, congestión intestinal $(60 \%)$ y hemorragias en boca (50\%) (Cuadro 4). Las mortalidades se iniciaron al $2^{\circ}$ dpi en $\mathrm{G} 3$ y G4, y a los $7^{\circ}$ dpi en $\mathrm{G} 1$ y G2. La mortalidad total fue nula para el grupo control, y $65,60,100$ y $100 \%$ para G1, G2, G3 y G4 (Cuadro 5).

\section{Análisis Histopatológico}

A nivel del tejido hepático, se identificó degeneración grasa $(20 / 20)$ y necrosis $(20 / 20)$ (Figura 1A), en ambos de escaso a severo grado de presentación; asimismo, escasa a moderada congestión (19/20) (Figura 1B), escasa a leve presencia de melanomacrófagos $(5 / 20)$ (Figura 1A), leve presencia de bacterias extravasculares $(1 / 20)$ y moderada separación de hepatocitos (1/20) (Figura 1B) en los peces inoculados con Y. ruckeri. En el caso del grupo control, solo se observó leve degeneración grasa (5/5) (Cuadro 6). 
Cuadro 3. Índice de morbilidad de los grupos experimentales inoculados con $Y$. ruckeri $(\mathrm{n}=20$ por grupo)

\begin{tabular}{|c|c|c|c|c|c|}
\hline Día & C & G1 & G2 & G3 & G4 \\
\hline 1 & - & - & - & 7 & 9 \\
\hline 2 & - & - & - & 8 & 9 \\
\hline 3 & - & 3 & 3 & 5 & 2 \\
\hline 4 & - & 5 & 2 & - & - \\
\hline 5 & - & 4 & 5 & - & - \\
\hline 6 & - & 3 & 6 & - & - \\
\hline 7 & - & 4 & 2 & - & - \\
\hline 8 & - & 1 & 3 & - & - \\
\hline 9 & - & - & - & - & - \\
\hline 10 & - & - & - & - & - \\
\hline 11 & - & - & - & - & - \\
\hline 12 & - & - & & - & - \\
\hline Total & 0 & 20 & 20 & 20 & 20 \\
\hline
\end{tabular}

A nivel del bazo, en los peces inoculados, se identificó de leve a escaso grado de congestión $(20 / 20)$ y escasa a moderada presencia de melanomacrófagos (20/20) (Figura 2A). Adicionalmente, en menor frecuencia se observó leve presencia de bacterias (4/20), dilatación de vasos sanguíneos (3/20) (Figura 2B) y disminución linfoide (2/20) (Figura $2 \mathrm{C}$ ), ambas de grado moderado a severo. Además, de leve a moderada necrosis $(3 / 20)$ (Figura 2B) y moderada presencia de linfocitos lisados (2/20) (Figura 2C) (Cuadro 7). No se observaron lesiones en bazo en los peces del grupo control.

En el riñón anterior, se observó en los peces inoculados de leve a severa presencia de melanomacrófagos $(13 / 20)$, túbulos regenerados $(5 / 20)$ y disminución linfoide $(6 / 20)$ (Figura 3A), ambas de leve a moderado grado. Adicionalmente, moderada a severa necrosis $(6 / 20)$, escasa a moderada presencia de gotas hialinas en epitelio tubular (3/20) (Figura 3B), moderado aumento de tejido linfoide (2/20), congestión (2/20) (Figura 3C) y presencia de bacterias $(2 / 20)$, en ambos casos de leve a moderado grado y una moderada linfocitolisis (1/20) (Figura 3C). Se debe resaltar que en el grupo control también se observó diversos tipos de lesiones (Cuadro 8).

Cuadro 4. Frecuencia de lesiones externas e internas en truchas arcoíris inoculadas con Yersinia ruckeri $(\mathrm{n}=20$ peces por grupo)

\begin{tabular}{|c|c|c|c|c|c|c|}
\hline $\begin{array}{l}\text { Lesiones internas y } \\
\text { externas }\end{array}$ & $\begin{array}{l}\text { G1 } \\
(\mathrm{n})\end{array}$ & $\begin{array}{l}\text { G2 } \\
\text { (n) }\end{array}$ & $\begin{array}{l}\text { G3 } \\
\text { (n) }\end{array}$ & $\begin{array}{l}\text { G4 } \\
\text { (n) }\end{array}$ & $\begin{array}{l}\text { Total de casos } \\
\text { (n) }\end{array}$ & $\begin{array}{c}\text { Frecuencia } \\
(\%)\end{array}$ \\
\hline Esplenomegalia & 16 & 15 & 18 & 18 & 67 & 84 \\
\hline $\begin{array}{l}\text { Contenido mucoso en } \\
\text { intestino }\end{array}$ & 15 & 13 & 18 & 18 & 64 & 80 \\
\hline Congestión intestinal & 11 & 13 & 12 & 12 & 48 & 60 \\
\hline Hemorragias en boca & 8 & 9 & 11 & 12 & 40 & 50 \\
\hline $\begin{array}{l}\text { Petequias en músculo } \\
\text { y tejido graso }\end{array}$ & 8 & 7 & 10 & 13 & 38 & 48 \\
\hline Palidez hepática & 6 & 9 & 11 & 12 & 38 & 48 \\
\hline Hemorragia ocular & 10 & 10 & 6 & 8 & 34 & 43 \\
\hline Palidez branquial & 7 & 7 & 8 & 8 & 30 & 38 \\
\hline $\begin{array}{l}\text { Vejiga natatoria } \\
\text { hemorrágica }\end{array}$ & 7 & 7 & 6 & 5 & 25 & 31 \\
\hline Congestión hepática & 8 & 6 & 5 & 4 & 23 & 29 \\
\hline Petequias en hígado & 4 & 6 & 4 & 3 & 17 & 21 \\
\hline
\end{tabular}

G1: $1 \times 10^{4} ; \mathrm{G} 2: 4 \times 10^{4} ; \mathrm{G} 3: 1 \times 10^{8} ; \mathrm{G} 4: 4 \times 10^{8} / \mathrm{ml}$ 
Cuadro 5. Índice de mortalidad de los grupos experimentales inoculados con $Y$. ruckeri $(\mathrm{n}=20$ por grupo)

\begin{tabular}{cccccc}
\hline Día & C & G1 & G2 & G3 & G4 \\
\hline 1 & - & - & - & - & - \\
2 & - & - & - & 11 & 10 \\
3 & - & - & - & 5 & 8 \\
4 & - & - & - & 1 & 2 \\
5 & - & - & - & 2 & - \\
6 & - & - & - & 1 & - \\
7 & - & 1 & 1 & - & - \\
8 & - & 1 & 4 & - & - \\
9 & - & 3 & 3 & - & - \\
10 & - & 7 & 2 & - & - \\
11 & - & 1 & 1 & - & - \\
12 & - & - & 1 & - & - \\
\hline Total & 0 & 13 & 12 & 20 & 20 \\
\hline
\end{tabular}

C; control; G1: $1 \times 10^{4} ; \mathrm{G} 2: 4 \times 10^{4} ; \mathrm{G} 3: 1 \times 10^{8}$; G4: $4 \times 10^{8} / \mathrm{ml}$

A nivel intestinal se determinó en los peces inoculados severa necrosis $(20 / 20)$ (Figura 4A) en todas las muestras de peces infectados con Y. ruckeri; asimismo, se observó presencia de bacterias (2/20) e hiperplasia de enterocitos (2/20) (Figura 4B), en ambo casos de leve a severo grado de presentación. Además, disgregación del epitelio (1/20) y presencia de células granulares eosinofílicas $(1 / 20)$ (Figura 4A), ambas de grado severo, y leve hiperplasia de células caliciformes $(1 / 20)$ (Figura 4B). No se observaron lesiones en intestino en los peces del grupo control (Cuadro 9).

En el análisis de músculo se identificó en los peces inoculados de leve a severo grado de necrosis (11/20) (Figura 5A), escasa a moderada presencia de macrófagos y otras células inflamatorias (8/20) (Figura 5B). Además, se observó escasa a moderada presencia de bacterias $(3 / 20)$, disgregación de fibras musculares $(2 / 20)$ y dilatación de vasos (1/20) (Figura 5A), en ambos casos en grado leve. No se observaron lesiones en músculo en los peces del grupo control (Cuadro 10).

A nivel del tejido branquial se observó en los peces inoculados de escasa a moderada hiperplasia y fusión de lamelas $(13 / 20)$ y leve teleangiectasia (1/20) (Figura 6A), congestión $(3 / 20)$, presencia de melanomacrófagos (1/20) (Figura 6B), estas dos últimas en grado leve, y escasa hiperplasia del ápice de lamelas (1/20) (Figura 6C). No se observaron lesiones en tejido branquial en los peces del grupo control (Cuadro 11).

Cuadro 6. Hallazgos histopatológicos y su frecuencia relativa en hígado de truchas arcoíris (Oncorhynchus mykiss) inoculadas con Yersinia ruckeri

\begin{tabular}{lcccccc}
\hline Lesiones & $\begin{array}{c}\mathrm{C} \\
\mathrm{n}=5\end{array}$ & $\begin{array}{c}\mathrm{G} 1 \\
\mathrm{n}=5\end{array}$ & $\begin{array}{c}\mathrm{G} 2 \\
\mathrm{n}=5\end{array}$ & $\begin{array}{c}\mathrm{G} 3 \\
\mathrm{n}=5\end{array}$ & $\begin{array}{c}\mathrm{G} 4 \\
\mathrm{n}=5\end{array}$ & $\begin{array}{c}\text { Frecuencia } \\
(\%)\end{array}$ \\
\hline Degeneración grasa & 5 & 5 & 5 & 5 & 5 & 100 \\
Necrosis & 0 & 5 & 5 & 5 & 5 & 80 \\
Congestión & 0 & 5 & 4 & 5 & 5 & 76 \\
Melanomacrófagos & 0 & 2 & 1 & 1 & 1 & 20 \\
Presencia de bacterias & 0 & 0 & 0 & 0 & 1 & 4 \\
Separación de hepatocitos & 0 & 1 & 0 & 0 & 0 & 4 \\
\hline
\end{tabular}

C; control; G1: $1 \times 10^{4} ; \mathrm{G} 2: 4 \times 10^{4}$; G3: $1 \times 10^{8} ; \mathrm{G} 4: 4 \times 10^{8} / \mathrm{ml}$ 
Cuadro 7. Hallazgos histopatológicos y su frecuencia en bazo de truchas arcoíris (Oncorhynchus mykiss) inoculadas con Yersinia ruckeri

\begin{tabular}{lcccccc}
\hline Lesiones & $\begin{array}{c}\mathrm{C} \\
\mathrm{n}=5\end{array}$ & $\begin{array}{c}\mathrm{G} 1 \\
\mathrm{n}=5\end{array}$ & $\begin{array}{c}\mathrm{G} 2 \\
\mathrm{n}=5\end{array}$ & $\begin{array}{c}\mathrm{G} 3 \\
\mathrm{n}=5\end{array}$ & $\begin{array}{c}\mathrm{G} 4 \\
\mathrm{n}=5\end{array}$ & $\begin{array}{c}\text { Frecuencia } \\
(\%)\end{array}$ \\
\hline Congestión & 0 & 5 & 5 & 5 & 5 & 80 \\
Melanomacrófagos & 0 & 5 & 5 & 5 & 5 & 80 \\
Bacterias & 0 & 1 & 1 & 1 & 1 & 16 \\
Dilatación de vasos & 0 & 0 & 0 & 1 & 2 & 12 \\
$\quad$ sanguíneos & 0 & 1 & 2 & 0 & 0 & 12 \\
Necrosis & 0 & 1 & 1 & 0 & 0 & 8 \\
Disminución Linfoide & 0 & 1 & 0 & 0 & 1 & 8 \\
Linfocitos lisados & & & & & \\
\hline
\end{tabular}

C; control; G1: $1 \times 10^{4} ; \mathrm{G} 2: 4 \times 10^{4} ; \mathrm{G} 3: 1 \times 10^{8} ; \mathrm{G} 4: 4 \times 10^{8} / \mathrm{ml}$

Cuadro 8. Hallazgos histopatológicos y su frecuencia en riñón anterior de truchas arcoíris (Oncorhynchus mykiss) inoculadas con Yersinia ruckeri

\begin{tabular}{lcccccc}
\hline Lesiones & $\mathrm{C}$ & $\mathrm{G} 1$ & $\mathrm{G} 2$ & $\mathrm{G} 3$ & $\mathrm{G} 4$ & $\begin{array}{c}\text { Frecuencia } \\
(\%)\end{array}$ \\
\hline Melanomacrófagos & 2 & 4 & 2 & 4 & 3 & 60 \\
Túbulos regenerados & 2 & 2 & 0 & 2 & 1 & 28 \\
Necrosis & 0 & 2 & 0 & 2 & 2 & 24 \\
Disminución linfoide & 0 & 0 & 0 & 3 & 3 & 24 \\
Gotas hialinas en epitelio & 1 & 3 & 0 & 0 & 0 & 16 \\
$\quad$ tubular & & & & & & \\
Aumento de tejido linfoide & 0 & 0 & 2 & 0 & 0 & 8 \\
Bacterias & 0 & 1 & 0 & 0 & 1 & 8 \\
Congestión & 0 & 0 & 0 & 0 & 2 & 8 \\
Linfocitolisis & 0 & 1 & 0 & 0 & 0 & 4 \\
\hline
\end{tabular}

C; control; G1: $1 \times 10^{4} ; \mathrm{G} 2: 4 \times 10^{4} ; \mathrm{G} 3: 1 \times 10^{8} ; \mathrm{G} 4: 4 \times 10^{8} / \mathrm{ml}$

Cuadro 9. Hallazgos histopatológicos y su frecuencia en intestino de truchas arcoíris (Oncorhynchus mykiss) inoculadas con Yersinia ruckeri

\begin{tabular}{lcccccc}
\hline Lesiones & $\begin{array}{c}\mathrm{C} \\
\mathrm{n}=5\end{array}$ & $\begin{array}{c}\mathrm{G} 1 \\
\mathrm{n}=5\end{array}$ & $\begin{array}{c}\mathrm{G} 2 \\
\mathrm{n}=5\end{array}$ & $\begin{array}{c}\mathrm{G} 3 \\
\mathrm{n}=5\end{array}$ & $\begin{array}{c}\mathrm{G} 4 \\
\mathrm{n}=5\end{array}$ & $\begin{array}{c}\text { Frecuencia } \\
(\%)\end{array}$ \\
\hline Necrosis & 0 & 5 & 5 & 5 & 5 & 80 \\
Bacterias & 0 & 2 & 0 & 0 & 0 & 8 \\
Hiperplasia de enterocitos & 0 & 1 & 1 & 0 & 0 & 8 \\
Epitelio disgregado & 0 & 1 & 0 & 0 & 0 & 4 \\
Célula granular eosinofílica & 0 & 1 & 0 & 0 & 0 & 4 \\
$\begin{array}{l}\text { Hiperplasia de células } \\
\quad \text { caliciformes }\end{array}$ & 0 & 0 & 1 & 0 & 0 & 4 \\
\hline
\end{tabular}

C; control; G1: $1 \times 10^{4} ; \mathrm{G} 2: 4 \times 10^{4} ; \mathrm{G} 3: 1 \times 10^{8} ; \mathrm{G} 4: 4 \times 10^{8} / \mathrm{ml}$ 


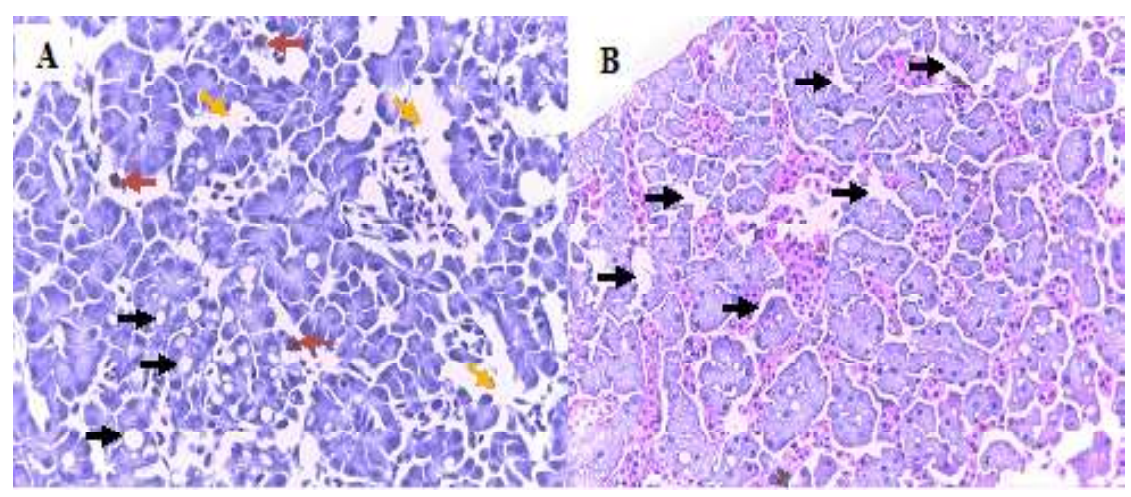

Figura 1. Cortes histológicos de hígado de trucha arcoíris (Oncorhynchus mykiss). A: Necrosis (flechas naranjas) con degeneración grasa (flechas negras) y presencia de melanomacrófagos (flechas rojas). B: Congestión con separación de hepatocitos (flechas negras). H-E. 400X

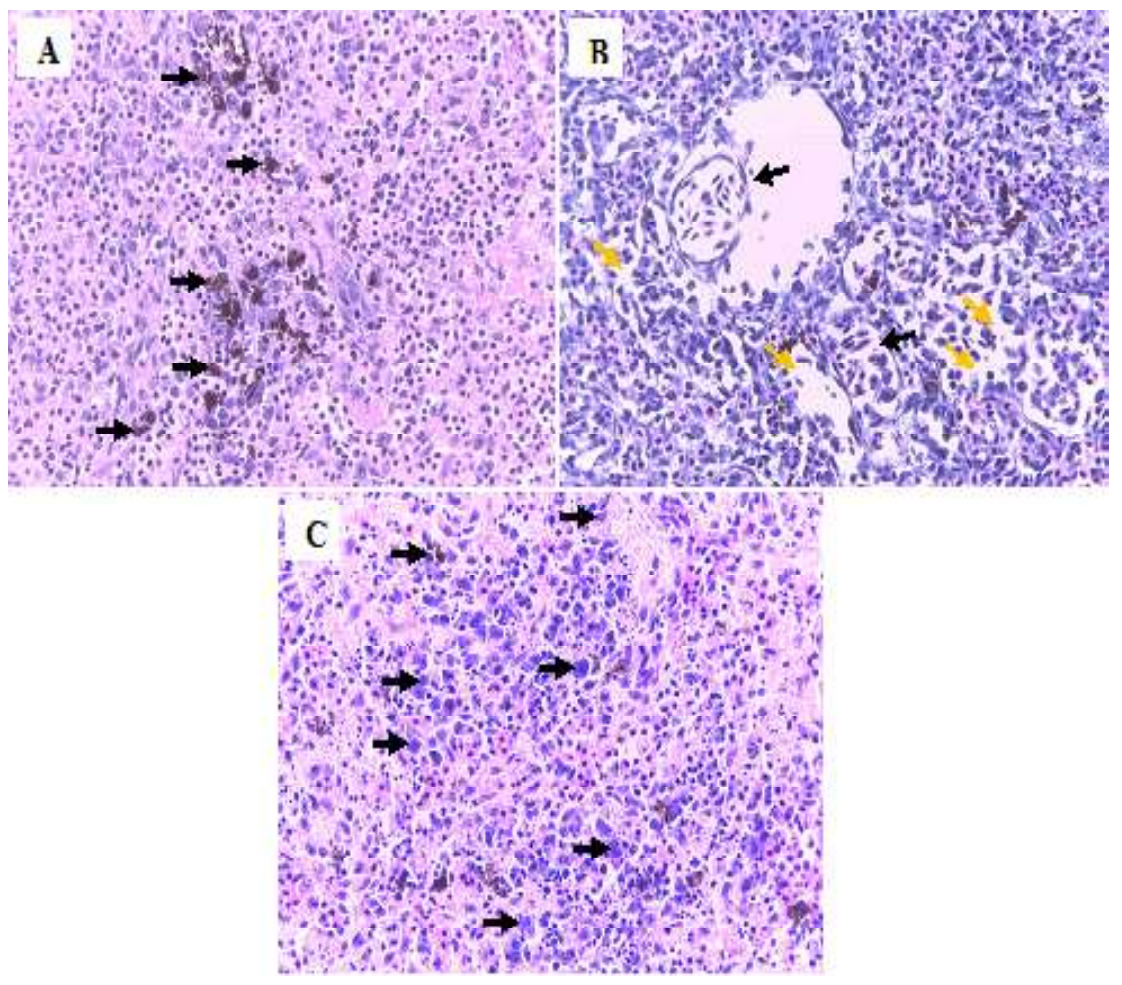

Figura 2. Cortes histológicos de bazo de trucha arcoíris (Oncorhynchus mykiss). A: Congestión con presencia de melanomacrófagos (flechas negras). B: Dilatación de vasos sanguíneos (flechas negras) con zonas de necrosis (flechas naranjas). C: Disminución linfoide con linfocitos lisados (flechas negras). H-E. 400X 


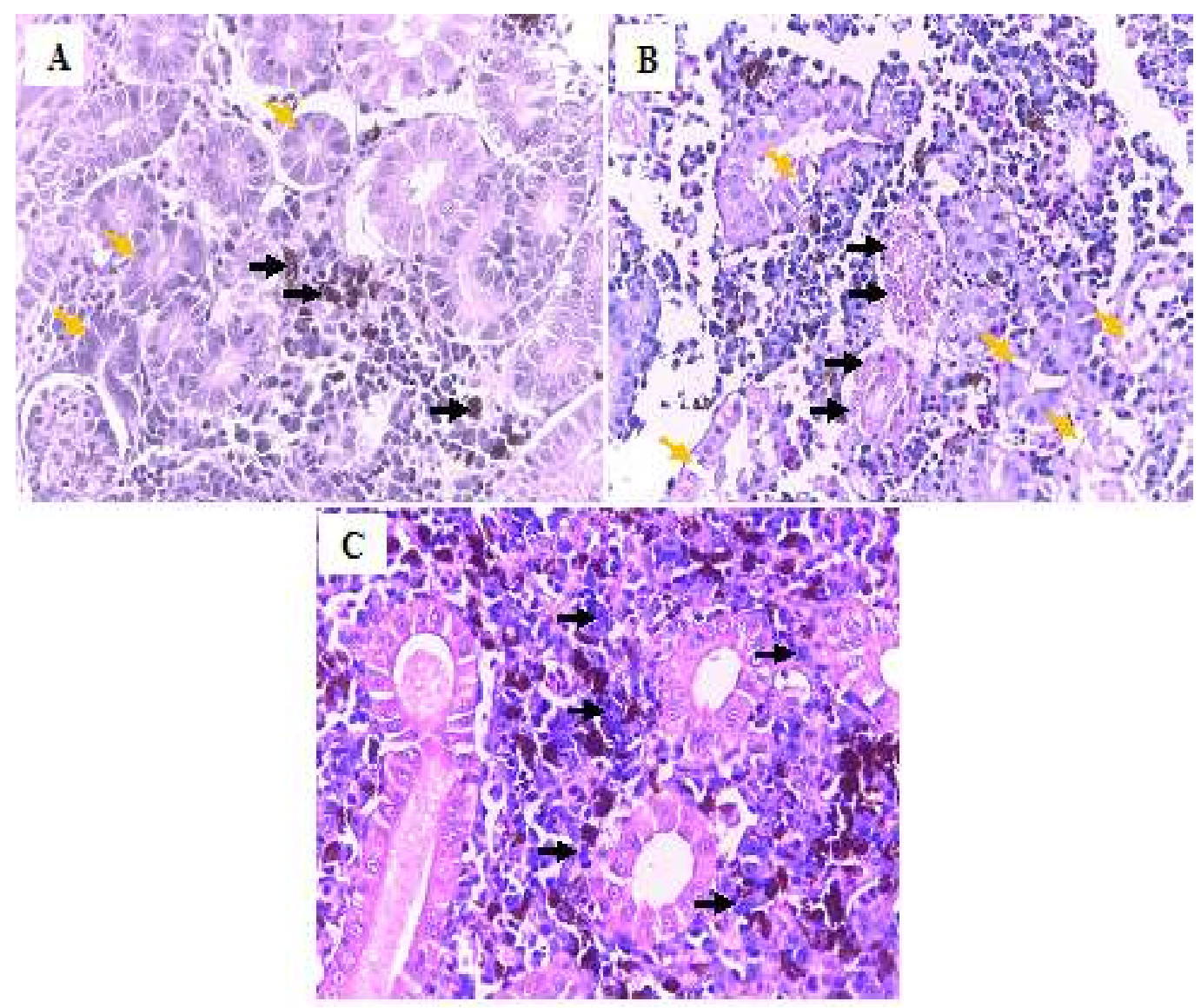

Figura 3. Cortes histológicos de riñón de trucha arcoíris (Oncorhynchus mykiss). A: Disminución de tejido linfoide con regeneración tubular (flechas naranjas) y presencia de melanomacrófagos (flechas negras). B: Necrosis tubular (flechas naranjas) con presencia de gotas hialinas (flechas negras). C: Congestión y aumento de tejido linfoide con presencia de linfocitos lisados (flechas negras). H-E. 400X

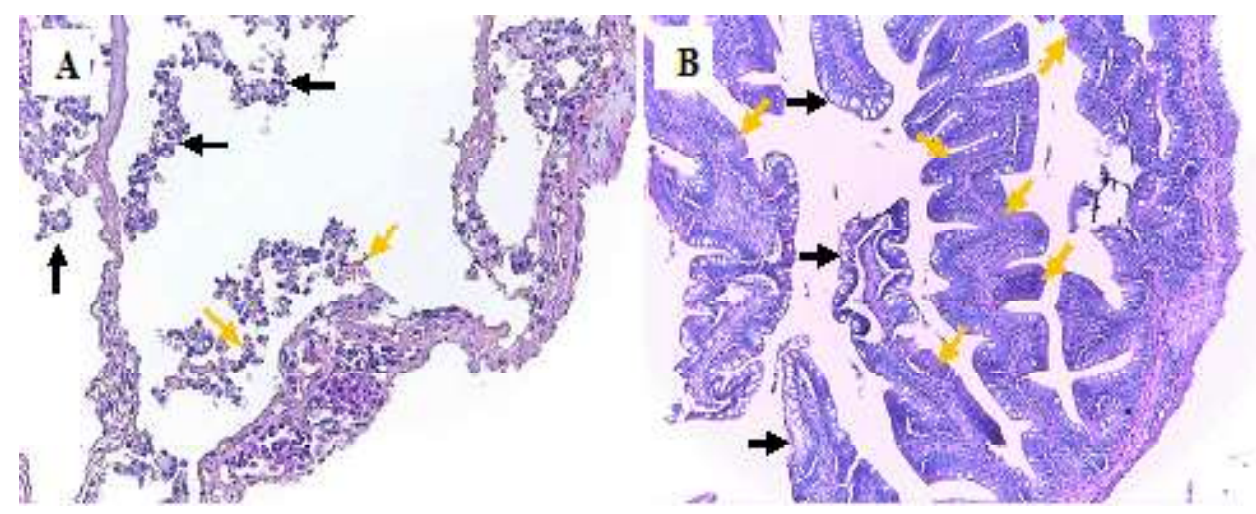

Figura 4. Cortes histológicos de intestino de trucha arcoíris (Oncorhynchus mykiss). A: Necrosis con epitelio disgregado (flechas negras) y células granulares eosinofílicas (flechas naranjas). H-E. 400X. B: Hiperplasia de enterocitos (flechas naranjas) con hiperplasia de células caliciformes (flechas negras). H-E. 100X 


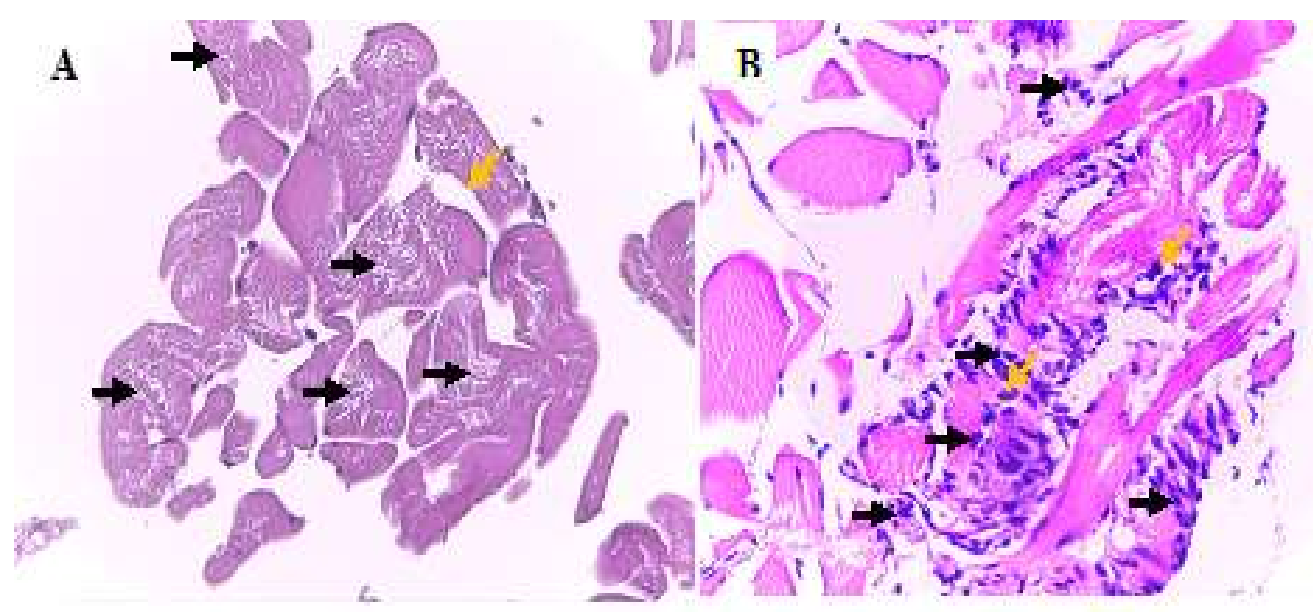

Figura 5. Cortes histológicos de músculo de trucha arcoíris (Oncorhynchus mykiss). A: Disgregación de fibras musculares con áreas de necrosis con (flechas negras) y dilatación de vaso sanguíneo (flecha naranja). B: Infiltración de macrófagos (flechas naranjas) y otras células inflamatorias (flechas negras). H-E. 400X

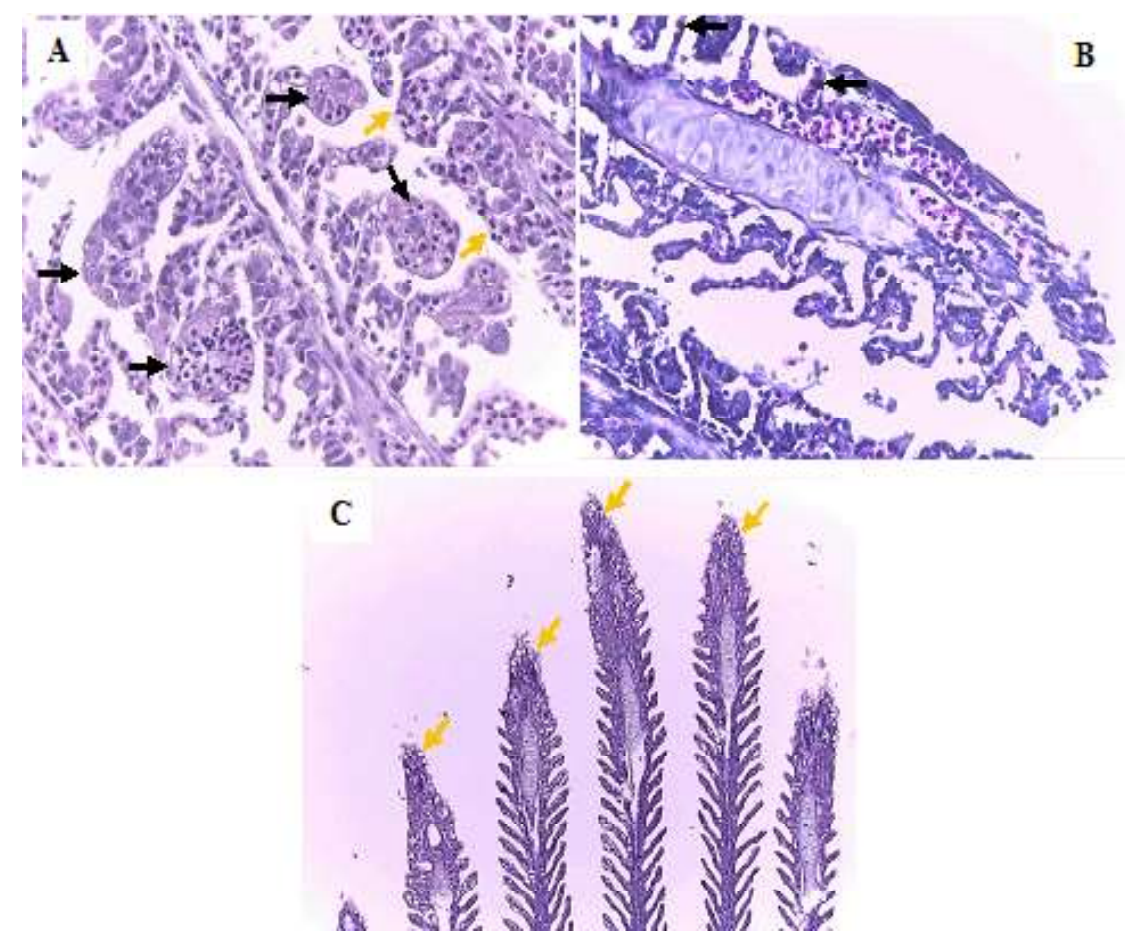

Figura 6. Cortes histológicos de branquias de trucha arcoíris (Oncorhynchus mykiss). A: Hiperplasia y fusión de lamelas (flechas naranjas) con teleangiectasia (flechas negras). B: Congestión con presencia de melanomacrófagos (flechas negras). H-E. 400X. C: Hiperplasia del ápice de las lamelas (flechas naranjas). H-E. 100X 
Cuadro 10. Hallazgos histopatológicos y su frecuencia en músculo de truchas arcoíris (Oncorhynchus mykiss) inoculadas con Yersinia ruckeri

\begin{tabular}{lcccccc}
\hline Lesiones & $\mathrm{C}$ & $\mathrm{G} 1$ & $\mathrm{G} 2$ & $\mathrm{G} 3$ & $\mathrm{G} 4$ & $\begin{array}{c}\text { Frecuencia } \\
(\%)\end{array}$ \\
\hline Necrosis & 0 & 4 & 4 & 5 & 5 & 44 \\
$\quad \begin{array}{l}\mathrm{n}=5 \\
\quad \text { Infiltración de }\end{array}$ & 0 & 1 & 1 & 4 & 2 & 32 \\
$\quad$ melanomacrófagos y & & & & & & \\
$\quad$ otras cél. inflamatorias & & & & & & 12 \\
$\begin{array}{l}\text { Bacterias } \\
\text { Disgregación de fibras }\end{array}$ & 0 & 0 & 0 & 1 & 2 & 8 \\
$\quad$ musculares & 0 & 2 & 0 & 0 & 0 & 4 \\
$\quad$ Dilatación de vasos & 0 & 1 & 0 & 0 & 0 & 4 \\
\hline
\end{tabular}

C; control; G1: $1 \times 10^{4}$; G2: $4 \times 10^{4} ; \mathrm{G} 3: 1 \times 10^{8} ; \mathrm{G} 4: 4 \times 10^{8} / \mathrm{ml}$

Cuadro 11. Hallazgos histopatológicos y su frecuencia en branquias de truchas arcoíris (Oncorhynchus mykiss) inoculadas con Yersinia ruckeri

\begin{tabular}{lcccccc}
\hline Lesiones & $\mathrm{C}$ & $\mathrm{G} 1$ & $\mathrm{G} 2$ & $\mathrm{G} 3$ & $\begin{array}{c}\mathrm{G} 4 \\
\mathrm{n}=5\end{array}$ & $\begin{array}{c}\text { Frecuencia } \\
(\%)\end{array}$ \\
\hline $\begin{array}{l}\text { Hiperplasia y fusión de } \\
\quad \text { lamelas }\end{array}$ & 0 & 2 & 3 & 3 & 5 & 52 \\
$\begin{array}{l}\text { Congestión } \\
\begin{array}{c}\text { Presencia de } \\
\quad \text { melanomacrófagos }\end{array}\end{array}$ & 0 & 0 & 1 & 1 & 1 & 12 \\
$\begin{array}{c}\text { Hiperplasia ápice de } \\
\quad \text { lamelas }\end{array}$ & 0 & 1 & 0 & 0 & 0 & 4 \\
Teleangiectasia & 0 & 0 & 0 & 0 & 1 & 4 \\
\hline
\end{tabular}

C; control; G1: $1 \times 10^{4} ; \mathrm{G} 2: 4 \times 10^{4} ; \mathrm{G} 3: 1 \times 10^{8} ; \mathrm{G} 4: 4 \times 10^{8} / \mathrm{ml}$

\section{Discusión}

La cepa de $Y$. ruckeri mostró una alta patogenicidad en alevines, causando septicemias agudas con mortalidades del $50 \%$ al segundo día de inoculado en dosis de $1 \times 10^{8}$, demostrando ser la causante de la epizootia de yersiniosis que causó mortalidades de 60$70 \%$ en pozas de diversas piscigranjas de Huaraz, tanto en alevines como en otros grupos etarios, indicando una patogenicidad inusual en el campo. 
Los principales signos clínicos observados (anorexia, melanosis, letargo y exoftalmia) son signos generales de un pez enfermo y no patognomónico de yersiniosis. Estos también fueron reportados en retos experimentales con Y. ruckeri, sin que se hayan mencionado los momentos pos-inoculación en que hayan aparecido (Tobback et al., 2009; Mahjoor y Akhlaghi, 2012; Cueva, 2015). Así mismo, se ha reportado que $Y$. ruckeri puede provocar severa afección cerebral (Ohtani et al., 2014), produciendo signos nerviosos, como nado errático y en tirabuzón, los cuales fueron encontrados en este y otros estudios (Avci y Birincioðlu, 2005). Además, Y. ruckeri provoca lesiones edematosas en las glándulas coroidales con acumulación de líquido intraocular (Busch, 1978), lo que explicaría la exoftalmia encontrada en este estudio.

La rápida presentación de signos clínicos en peces de G3 y G4 fue más rápida a lo reportado por Seeker et al. (2011), quienes describen signos similares, pero a partir del tercer día para dosis altas de Y. ruckeri $\left(1 \times 10^{8}\right.$ y $\left.4 \times 10^{8}\right)$. En el caso de G1 y G2, estos signos se presentaron al tercer día, de forma y orden similar a los grupos G3 y G4, y a lo reportado por Austin B y Austin D (2016). Los signos clínicos de yersiniosis y su temprana aparición en los grupos G3 y G4, no solo estarían relacionados a las altas concentraciones inoculadas, sino también a la alta patogenicidad de la cepa en estudio, lo cual se evidencia en las lesiones ocasionadas.

Todas las truchas inoculadas con $Y$. ruckeri presentaron lesiones típicas de la enfermedad de la boca roja. Las lesiones que se observaron en los cuatro grupos fueron esplenomegalia, contenido mucoso en intestino y congestión intestinal, que también han sido descritas por Tobback et al. (2009), Seeker et al. (2011) y Cueva (2015); lo que confirma la patogenicidad de esta cepa a bajas concentraciones. Por otra parte, el 50\% de los peces infectados presentaron hemorragias alrededor o dentro de la cavidad oral, lo que le da el nombre característico de «boca roja» a esta enfermedad. Avci y Birincioglu (2005) y Cueva (2015) tampoco encontraron estas lesiones en todos los peces inoculados. Las lesiones menos frecuentes halladas en este estudio coinciden con las observaciones de otros autores (Barnes, 2011; Sakai et al., 2012; Mahjoor y Akhlaghi, 2012; Mateo et al., 2016). Estas lesiones estarían asociadas a los factores de virulencia que tiene $Y$. ruckeri, como toxinas extracelulares, adhesinas e invasinas y ruckerbactina, entre otros (Fernández et al., 2007; Ryckaert et al., 2010; Barnes, 2011)

Si bien se obtuvo el $100 \%$ de mortalidad en G3 y G4, las mortalidades también fueron altas en los grupos G1 y G2, a pesar de las bajas concentraciones de Y. ruckeri (1x $10^{4}$ y $4 \times 10^{4} / \mathrm{ml}$, respectivamente). Berc et al. (1999) utilizaron una dosis menor $\left(5 \times 10^{5} / \mathrm{ml}\right)$ en carpas inoculadas intraperitoneal produciendo una enfermedad septicémica. Las mortalidades comenzaron a los 3 dpi para los grupos G3 y G4, y a los 6 dpi para los grupos G1 y G2. El índice de mortalidad y la rapidez de presentación no solo pueden atribuirse a la alta concentración utilizada en este estudio, dado que con concentraciones bajas en G1 y G2 también se produjo mortalidad con signos clínicos y lesiones, dada la alta patogenicidad de la cepa en estudio.

El retraso en la manifestaciones clínicas de enfermedad a dosis menores (G1 y G2) y la sobrevivencia de $35-40 \%$ de alevines infectados se debería a la respuesta inmune de los peces, ya que se ha demostrado que los dos biotipos de Y. ruckeri inducen la producción de TNF- $\alpha 1$ e IL1- $\beta 1$ desde el primer día del desafío y tienen una máxima expresión de los genes a los 3, 5 y 7 días en el bazo, induciendo a una respuesta inmune innata en los peces infectados con bajas dosis. Por otro lado, a altas dosis, la expresión de los genes de las proteínas de la superfamilia de TNF son regulados negativamente (downregulated) a los 3, 5 y 7 días pos-infección (Wiens y Vallejo, 2010), siendo esta una de las causas de las altas mortalidades por las dosis altas utilizadas en este trabajo. 
En este estudio se logró visualizar lesiones en bazo con presencia de bacterias, tanto en el parénquima como en los vasos sanguíneos, lo cual prueba la septicemia bacteriana de manera similar a las descritas por Tinsley et al. (2011), Mahjoor y Akhlaghi (2012) y Sierralta et al. (2013). Además, se pudo observar una moderada congestión, necrosis y degeneración grasa, así como la presencia de melanomacrófagos en hígado, mayormente en los alevines de G3 y G4. La degeneración grasa hepática ha sido descrita para animales con infección crónica por $Y$. ruckeri (Avci y Birincioðlu, 2005; Tinsley et al., 2011).

Se observó regeneración tubular en el riñón e incremento de celularidad leucocitaria, similar a los hallazgos reportados por Tinsley et al. (2011) y Avci y Birincioðlu (2005), respectivamente. Además, se reporta la proliferación de células mononucleares en infecciones crónicas experimentales y en brotes de campo (Tobback, 2007; Mahjoor y Akhlaghi, 2012), necrosis intestinal con desprendimiento de la mucosa (Mahjoor y Akhlaghi, 2012; Sierralta et al., 2013).

La presencia de melanomacrófagos en bajo número en riñón, bazo e hígado se considera normal en algunas especies de peces, pero su incremento está asociado a infecciones crónicas (Agius y Roberts, 2003). En el presente estudio estuvieron presentes en estos tejidos; sin embargo, de manera leve a severa, y de acuerdo con las dosis inoculantes, ya que estas células poseen capacidad de fagocitar antígenos; así mismo, esto conlleva a estimular la respuesta inmune adaptativa (Press y Evensen, 1999): Por otro lado, su incremento ha sido descrito en truchas sobrevivientes a infecciones con Y. ruckeri (Tobback et al., 2009; Cueva, 2015).

La vía intramuscular como sitio de inoculación en este y otros estudios experimentales, evidenciaron leve a severa necrosis de las fibras musculares, con presencia de células inflamatorias y bacterias. Esta lesión se debe a que $Y$. ruckeri produce una proteasa Yrp1, la cual es capaz de degradar fibronectina, actina y miosina, dañando así las fibras musculares y produciendo, además, su disgregación (Fernández et al., 2007; Austin B y Austin D, 2016).

Las lesiones en branquias como congestión, teleangiectasia, hiperplasia y fusión de lamelas así como del ápice lamelar, son similares a las reportadas en la literatura (Berc et al., 1999; Tinsley et al., 2011). Tobback et al. (2009) y Ohtani et al. (2014) demostraron que por la vía branquial ocurre una rápida e importante captación de antígenos de $Y$. ruckeri, lo que lleva a suponer que las lesiones observadas son producto de la inoculación de esta bacteria. No obstante, Avci y Birincioglu (2005) indicaron que la hiperplasia interlamelar en truchas desafiadas contra $Y$. ruckeri fueron atípicas para la enfermedad y fueron asociadas, en cambio, a mala calidad del agua. Para este trabajo, los parámetros fisicoquímicos del agua fueron óptimos para el desarrollo de truchas arcoíris, con la excepción de los niveles de amonio-nitrógeno, los cuales se encontraban elevados, pero en un rango subletal. Niveles subletales de amonio en agua $(2-5 \mathrm{mg} / \mathrm{l})$ provocan hiperemia y fusión de lamelas secundarias en tilapias nilóticas (Benli et al., 2008).

\section{Conclusiones}

- La cepa móvil de Yersinia ruckeri procedente de Huaraz, Perú, es altamente patógena, produciendo mortalidad y diversas lesiones en tejidos de truchas arcoíris (Oncorhynchus mykiss) en condiciones experimentales.

- La cepa de Y. ruckeri inoculada experimentalmente a bajas concentraciones produce mortalidad y lesiones anatomopatológicas en alevines de truchas arcoíris como las descritas en yersiniosis septicémicas naturales, como lesiones hemorrágicas bucales (boca roja) en el $50 \%$ de peces infectados y mortalidad 
en un periodo de hasta 12 días.

- Altas concentraciones de Y. ruckeri $\left(1 \times 10^{8} / \mathrm{ml}\right.$ y $\left.4 \times 10^{8} / \mathrm{ml}\right)$ producen infecciones septicémicas agudas con altas mortalidades y lesiones en diversos tejidos de truchas arcoíris en un corto periodo (2 a 6 días).

\section{Agradecimientos}

Los autores manifiestan su agradecimiento al Vicerrectorado de Investigación de la Universidad Nacional Mayor de San Marcos por el financiamiento de este estudio.

\section{Literatura Citada}

1. Agius C, Roberts R. 2003. Melanomacrophage centres and their role in fish pathology. J Fish Dis 26: 499-509. doi: 10.1046/j.1365-2761.2003.00485.x

2. Austin B, Austin D. 2016. Bacterial fish pathogens: diseases of farmed and wild fish. $6^{\text {th }}$ ed. Switzerland: Springer. $366 \mathrm{p}$.

3. Avci H, Birincioçlu SS. 2005. Pathological findings in rainbow trout (Oncorhynchus mykiss, Walbaum 1792) experimentally infected with Yersinia ruckeri. Turk J Vet Anim Sci 29: 1321-1328.

4. Barnes A. 2011. Enteric redmouth disease (Yersinia ruckeri). In: Woo P, Bruno D (eds). Fish diseases and disorders: viral, bacterial and fungal infections. $2^{\text {nd }}$ ed. UK: CABI. p 484-511.

5. Benli AC, Köksal G, Ö̈ku A. 2008. Subletal ammonia exposure of Nile tilapia (Oreochromis niloticus L.): effects on gill, liver and kidney histology. Chemosphere 72: 1355-1358. doi: 10.1016/ j.chemosphere.2008.04.037

6. Berc A, Petrinec $Z$, Matasin $Z$, Kozarice Z. 1999. Yersinia ruckeri septicaemia in experimentally infected carp (Cyprinus carpio L) fingerlings. Acta Vet Hung 47: 161-172. doi: 10.1556/ 004.47.1999.2.2
7. Bland JM, Altman DG. 1986. Statistical methods for assessing agreement between two methods of clinical measurement. Lancet 327: 307-310. doi: 10.1016/S0140-6736(86)90837-8

8. Bravo S, Kojagura V. 2004. First isolation of Yersinia ruckeri from rainbow trout (Oncorhynchus mykiss) in Peru. Bull Eur Assn Fish P 24: 104-108.

9. Busch RS, Lingg AJ. 1975. Establishment of an asymptomatic carrier state infection of enteric redmouth disease in rainbow trout (Salmo gairdneri). J Fish Res Board Can 32: 2429-2432. doi: $10.1139 / 775-279$

10. Busch R. 1978. Enteric redmouth disease (Hagerman strain). Mar Fish Rev 40: 42-51.

11. Castro G, Ramos F, Uribe J, Manchego A, Sandoval N. 2017. Aislamiento de Yersinia ruckeri en truchas arcoiris (Oncorhynchus mykiss) provenientes de una piscigranja de la ciudad Chachapoyas, Amazonas. En: IC Conferencia Internacional Sanidad e Inocuidad de la Pesca y la Acuicultura CISIPA 2017. Lima: SANIPES-PRODUCE.

12. Cerro L, Manchego A, Ñũure J, Pihue J, Sandoval N. 2017. Estudio de sensibilidad antibiótica de diferentes cepas de Yersinia ruckeri procedentes de diferentes regiones del país. En: CISIPA 2017. Lima: SANIPES-PRODUCE.

13. Cueva A. 2015. Eficacia de dos métodos de administración de una vacuna contra Yersinia ruckeri en truchas arcoíris (Oncorhynchus mykiss). Tesis de Médico Veterinario. Lima: Univ. Nacional Mayor de San Marcos. 100 p.

14. Davies RL. 1990. O-serotyping of Yersinia ruckeri with special emphasis on European isolates. Vet Microbiol 22: 299-307. doi: 10.1016/0378-1135(90)90016-O

15. Fernández L, Méndez J, Guijarro J. 2007. Molecular virulence mechanisms of the fish pathogen Yersinia ruckeri. Vet Microbiol 125: 1-10. doi: 10.1016/ j.vetmic.2007.06.013 
16. Flores K. 2013. Determinación de la diversidad fenotípica de Yersinia ruckeri en aislados de trucha arcoíris (Oncorhynchus mykiss) de cultivo de las regiones de Junín, Ancash y Huancavelica. Tesis de Médico Veterinario. Lima: Univ. Nacional Mayor de San Marcos. 66 p.

17. Gibello A, Blanco MM, Moreno MA, Cutuli MT, Domenech A, Domínguez L, Fernández-Garayzábal JF. 1999. Development of a PCR assay for detection of Yersinia ruckeri in tissues of inoculated and naturally infected trout. Appl Environ Microb 65: 346-350.

18. Kumar G, Menanteau-Ledouble S, Saleh M, El-Matbouli M. 2015. Yersinia ruckeri, the causative agent of enteric redmouth disease in fish. Vet Res 46: 2-6. doi: 10.1186/s13567-015-0238-4

19. Mahjoor AA, Akhlaghi M. 2012. A pathological study of rainbow trout organs naturally infected with enteric redmouth disease. Asian J Anim Sci 6: 147-153. doi: 10.3923/ajas.2012.147.153

20. Mateo EC, Castro T, Sierralta V, Mateo DR. 2016. Bacteriological and histopathological study of farmed rainbow trout, Oncorhynchus mykiss, in Peru. J Fish Dis 40: 941-946. doi: 10.1111/jfd. 12555

21. Meyers T. 2009. Standard necropsy procedures for finfish. In: Heil N (ed). National wild fish health survey Laboratory procedures manual. $5^{\text {th }}$ ed. USA: Warm Springs. p 64-74.

22. Ohtani M, Villumsen $K$, Strom H, Raida M. 2014. 3D visualization of the initial Yersinia ruckeri infection route in rainbow trout (Oncorhynchus mykiss) by optical projection tomography. Plos One 9: e89672. doi: 10.1371/journal.pone. 0089672

23. Press CM, Evensen Ø. 1999. The morphology of the immune system in teleost fishes. Fish Shellfish Imm 9: 309318. doi: 10.1006/fsim.1998.0181

24. Reimschuessel R, May E, Bennett R, Lypsky M. 1992. Communications: a classification system for histological lesions. J Aquat Anim Health 4: 135: 143. doi: 10.1577/1548-8667(1992)-004<0135: $\mathrm{CACSFH}>2.3 . \mathrm{CO} ; 2$

25. Roberts M. 1983. A report of an epizootic in hatchery reared rainbow trout, Salmo gairdneri Richardson, at an English trout farm, caused by Yersinia ruckeri. J Fish Dis 6: 551-552. doi: 10.1111/j.1365-2761.1983.tb00111.x

26. Rosenthal S, Sandoval N, Gavidia C, Tabacchi L. 2013. Frecuencia de lipidosis hepática en truchas arcoíris (Oncorhynchus mykiss) de fase juvenil en una piscigranja de la sierra central del Perú. Rev Inv Vet Peru 24: 118-124. doi: 10.15381/rivep.v24i1.1675

27. Ross L, Ross B. 2008. Anaesthetic and sedative techniques for aquatic animals. $3^{\text {rd }}$ ed. UK: Blackwell. 222 p.

28. Rucker RR. 1966. Redmouth disease of rainbow trout (Salmo gairdneri). Bull Off Int Epizooties 65: 825-830.

29. Ryckaert J, Bossier P, D'herde K, Diez-Fraile A, Sorgeloos P, Haesebrouck F, Pasmans F. 2010. Persistence of Yersinia ruckeri in trout macrophages. Fish Shellfish Immun 29: 648-655. doi: 10.1016/j.fsi.2010.06.009

30. Sakai T, Nakayasu C, Ito T, Miwa S, Oseko N, Iida T. 2012. Virulence of Yersinia ruckeri for four indigenous fish species in Japan. Fish Pathol 47: 74-79. doi: $10.3147 /$ jsfp. 47.74

31. Sandoval N, Llanco L, Manchego A, Mesías F. 2016. Determinación de Yersinia ruckeri y susceptibilidad antimicrobiana en alevines de truchas arcoíris cultivadas en el lago Titicaca-Puno. En: LACQUA-SARA 2016. Lima: World Aquaculture Society.

32. Seker E, Karahan M, Çetinkaya B. 2011. Detection of Yersinia ruckeri by polymerase chain reaction (PCR) in infected rainbow trout (Oncorhynchus mykiss). J Anim Plant Sci 21: 570-574.

33. Sierralta V, León J, De Blas I, Bastardo A, Romalde JL, Castro T, Mateo E. 2013. Patología e identificación de Yersinia ruckeri en trucha arcoíris (Oncorhynchus mykiss) en piscigranjas de Junín, Perú. AquaTIC 38: 28-45. 
34. Sirvas-Cornejo S, Sánchez-Robinet CC, Peña-Domínguez C. 2011. Diagnóstico e identificación rápidos por PCR de Yersinia ruckeri aislada de Oncorhynchus mykiss procedentes de Canta, Lima, Perú. Rev Perú Biol 18: 349-353. doi: 10.15381/rpb.v18i3.451

35. Tinsley J, Lyndon A, Austin B. 2011. Antigenic and cross-protection studies of biotype 1 and biotype 2 isolates of Yersinia ruckeri in rainbow trout, Oncorhynchus mykiss (Walbaum). J App Microbiol 111: 8-16. doi: 10.1111/ j.1365-2672.2011.05020.x

36. Tobback E, Decostere A, Hermans K, Haesesbrouck F, Chiers K. 2007. Yersinia ruckeri infections in salmonid fish. J Fish Dis 30: 257-268. doi: 10.1111/ j.1365-2761.2007.00816.x

37. Tobback E, Decostere A, Hermans K, Haesesbrouck F, Chiers K. 2009. Route of entry and tissue distribution of
Yersinia ruckeri in experimentally infected rainbow trout Oncorhynchus mykiss. Dis Aquat Organ 84: 219-228. doi: 10.3354/dao02057

38. Welch TJ, Verner-Jeffreys $D W$, Dalsgaard I, Wiklund T, Evenhuis JP, Garcia JAC, et al. 2011. Independent emergence of Yersinia ruckeri biotype 2 in the United States and Europe. Appl Environ Microb 77: 3493-3499. doi: 10.1128/AEM.02997-10

39. Wiens GD, Vallejo RL. 2010. Temporal and pathogen-load dependent changes in rainbow trout (Oncorhynchus mykiss) immune response traits following challenge with biotype 2 Yersinia ruckeri. Fish Shellfish Immunol 29: 639647. doi: 10.1016/j.fsi.2010.06.010

40. Willumsen B. 1989. Birds and wild fish as potential vectors of Yersinia ruckeri. J Fish Dis 12: 275-277. doi: 10.1111/ j.1365-2761.1989.tb00313.x 